\title{
PANDEMIAS, QUARENTENAS E CONTÁGIOS!
}

\author{
Júlia Maria Guilherme Ribeiro Antunes \\ Médica e Médica Dentista \\ Instituto Universitário Egas Moniz \\ Prof. Auxiliar \\ julia@antunes.net
}

Recepción Artículo: 27 octubre 2021 Admisión Evaluación: 27 octubre 2021 Informe Evaluador 1: 28 octubre 2021 Informe Evaluador 2: 29 octubre 2021 Aprobación Publicación: 30 octubre 2021

\section{RESUMO}

Entre as grandes interrogações da Humanidade está o porquê das pragas das pestes da fome e das guerras, o sofrimento e 0 mal acercam-se periódicamente das sociedades humanas assumindo desumanidades incompreensíveis desde os tempos mais remotos, referidas no Antigo Testamento, as pandemias tão antigas e afinal tão presentes nos nossos dias, conferem um certificado de capacidade repetitiva do Mal que no nosso tempo tentamos dissipar, permitindo o menor estrago possivel.

São Roque, socorrista dos contagiados da peste negra e também por ela contagiado, seria a quem os fiéis mais recorriam no séc. XIV, bem como para qualquer mal epidémico e contagioso objecto de orações promessas e novenas! Já o recurso ás quarentenas no tempo das Descobertas, revelar-se-ia muito útil e eficaz, era a Prevenção a iniciar os primeiros passos, inicialmente entre marinheiros e viajantes!

Os textos Bizatinos sobre epidemias eram cépticos relativamente ao contágio, contráriamente aos muçulmanos que 0 aceitavam desde tempos remotos, porém por mais sabedoras que fossem as explicações naturais, os paradoxos persistiam e persistem, como pode Deus infinitamente bom e poderoso, semear na Terra a peste, a cólera, a influenza, a sida, a covid-19?

Celebrado por católicos, ortodoxos e luteranos, S. João Damasceno diria que Deus seria criador de todos os bens mas não do mal sendo este devido aos maus usos do livre arbítrio praticado pelos homens ou apenas atribuído ao fatalismo pelos muçulmanos.

Crentes, heréticos, e muitos outros, perante a ameaça de um Apocalipse, esperam e desesperam segundo as próprias ideias, crenças, empirismo versus racionalismo do momento, porém uma coisa é certa: inexplicávelmente as epidemias e pandemias subitamente param, dissipam-se, desaparecem SEM sabermos porquê, como afirma Didier Raoul, médico de Marselha e acrescentaria, será que também são necessárias na bagagem humana, para atravessar a barreira do Tempo?

Palavras chave: pandemias; quarentenas; contágios 


\section{PANDEMIAS, QUARENTENAS E CONTÁGIOS!}

\section{ABSTRACT}

Pandemics, quarantines and contagions! Among the great questions of Humanity is why the plagues of famine and wars, suffering and evil periodically approach human societies, assuming incomprehensible inhumanities from the most remote times, referred to in the Old Testament, the pandemics so ancient and after all, so present in our days, they confer a certificate of Evil's repetitive capacity that in our time we try to dissipate, allowing as little damage as possible. São Roque, rescuer for those infected with the Black Death and also infected by it, would be the one to whom the faithful resorted most in the century. XIV, as well as for any epidemic and contagious disease, the object of prayers, promises and novenas! The recourse to quarantines at the time of the Discoveries, on the other hand, would prove to be very useful and effective, it was Prevention to initiate the first steps, initially among sailors and travelers! The Byzatine texts on epidemics were skeptical of contagion, contrary to Muslims who accepted it since ancient times, but however knowledgeable the natural explanations, the paradoxes persisted and persist, how can God infinitely good and powerful, sow the plague on Earth , cholera, influenza, AIDS, covid-19? Celebrated by Catholics, Orthodox and Lutherans, St. John Damascene would say that God would be the creator of all goods but not evil, this being due to the misuse of free will practiced by men or simply attributed to fatalism by Muslims. Believers, heretics, and many others, facing the threat of an Apocalypse wait and despair according to their own ideas, beliefs, empiricism versus rationalism of the moment, but one thing is certain: inexplicably epidemics and pandemics suddenly stop, dissipate, disappear SEM to know why, as Didier Raoul, a doctor from Marseilles, and I would add, are they also necessary in human baggage, to cross the barrier of Time?

Keywords: pandemics; quarantines; contagions

\section{INTRODUÇÃO}

Momentos de Apocalipse apresentaram-se naqueles tempos e ainda hoje, a grandes, pequenos, senhores e servos, reis e mendigos que aceitavam tão brusca morte com alegria sendo que o Papa através de confessores aos moribundos concedia a absolvição total de penas e castigos, concedia indulgências plenas, recolhia para a Igreja e religiosos as heranças e bens temporais, pois os herdeiros, parentes e filhos já haviam partido (Wheelis, 2002)

Entre 1346 e 1348, chineses, indianos, persas, mouros, curdos, arménios, silicianos, georgianos, mesopotâmicos, núbios, etíopes, turcos, egípcios, árabes, sarracenos e gregos acreditaram piamente ter chegado a hora do Juíso Final (Bellin, 2016)

Muitas epidemias chegaram pelo mar, os marinheiros contaminados fugiam e disseminavam as pestilências ao porem o pé em terra envenenando cada cidade, cada povoação, cada lugar morrendo homens mulheres e crianças, súbitamente, ficando a terra despovoada, todos eram agarrados pela Morte.

Entre a contaminação e a morte, dez dias, uma semana ou menos, a Yersinia Pestis viria a ser identificada por Alexandre Yersin em finais do sec. XIX, assumia a forma bubónica ou pneumónica , o médico do Papa Clemente VI, Guy de Chauliac dizia no seu tratado de Chirurgie Magna, a contaminação até pelo ar se transmitia, sem se tocar! (Marien, 2009)

A medicação off label simbolisa o desespero de encontrar solução para tratar a Covid-19, tão perto ainda de todos nós (Antunes, 2021)

Em Decameron, Boccaccio fala do colapso das familias, dos afetos dos comportamentos, perante este fantasma aparentemente invencível !Porém,o engenho e arte sempre nos acompanharam e eis que perante as pandemias,...se inventam as quarentenas para diminuir os contágios.

\section{PANDEMIAS}

As pandemias têm aparecido com maior frequência ultimamente, devido à aumentada emergência de agentes patogénicos de origem animal, particularmente vírus (Madhav et al., 2017), provocando quase dois terços das doenças infeciosas no ser humano. Este fenómeno é chamado de "zoonose" e o agente infecioso é apelidado de 
"zoonótico" (Porta, 2014), podendo constituir bactérias, fungos, parasitas, priões ou vírus e causar sintomas clínicos ou subclínicos (Fong, 2017). As zoonoses causam biliões de infeções e milhões de mortes anualmente (Karesh et al., 2012)

A incidência de zoonoses do tipo endémico tem aumentado nas últimas décadas devido às crescentes domesticações de animais, condições sanitárias desfavoráveis, movimentação humana entre países e cidades e também a sobrepopulação das mesmas (Fong, 2017).

No entanto, o surgimento de uma zoonose pode derivar de diversos fatores que resultam na invasão ou contato do ser humano em relação ao ambiente selvagem, como a industrialização, a expansão de comunidades, a migração populacional, conflitos políticos e bélicos e a fome ou subnutrição. Além destes fatores sócio-ecológicos, as características particulares do agente zoonótico, assim como as alterações climáticas, por sua vez, que acarretam alterações ecológicas, podem contribuir para a emergência de uma zoonose.

Deste modo, é necessária uma colaboração entre autoridades de saúde, autoridades e produtoras agrárias, gestores de recursos humanos e governos nacionais e locais para uma prevenção pandémica mais eficaz (Morse et al., 2012). A substituição do consumo de animais selvagens por animais domesticados, sem um controlo de infeção rigoroso, por exemplo, não permite uma prevenção adequada de uma zoonose, podendo inclusivamente introduzir novos microrganismos patogénicos nestas populações (Karesh et al., 2012).

É indispensável que haja uma análise virológica, médica, ecológica e sociológica dos fatores que podem afetar a emergência de uma pandemia zoonótica, a análise molecular de agentes patogénicos potencialmente pandémicos, quando combinada com estudos clínicos e epidemiológicos, também é um importante passo na predição da emergência de uma pandemia.

Desta forma, existem diversos critérios para melhorar a capacidade de prevenção, incluindo uma pesquisa sobre a proximidade entre o hospedeiro e 0 agente patogénico, a frequência de contato entre ambos e a proximidade entre 0 vírus zoonótico com os vírus humanos como fator preditor pandémico. Adicionalmente, sugerem a consideração de fatores como a variedade de hospedeiros e plasticidade da transmissão entre os mesmos, a interação com recetor do hospedeiro, a capacidade de evolução do vírus e do mesmo aderir a novas rotas de transmissão, a predição de virulência em seres humanos, tanto em severidade, como em transmissibilidade e padrões de co-evolução entre vírus e hospedeiro.

0 programa Emerging Pandemic Threats desenvolvido pela Agência dos Estados Unidos para 0 Desenvolvimento Internacional, incorpora algumas destas medidas, através da vigilância pela internet, assim como da recolha e análise de amostras, de forma a emitir um alerta global para doenças zoonóticas quando as mesmas emergem. Um dos seus projetos, designado PREDICT incorpora o conceito One Health que defende a interligação holística de várias disciplinas que, por sua vez, permitem uma melhor compreensão dos sistemas ecológicos e da origem e evolução de doenças infeciosas, que geralmente afetam humanos e animais. Além destes elementos, são incorporados também conhecimentos sobre a flora e 0 ambiente, cuja mudança, principalmente sob pressões antropogénicas, afeta a geografia animal, podendo aproximá-la da geografia humana (Kelly et al., 2020).

0 PREDICT consiste numa plataforma à qual governos, universidades e entidades de saúde e vigilância humana, animal e ambiental têm acesso, permitindo a partilha de novos dados, como surtos de doenças infeciosas, dados que levantem essa suspeita (por exemplo, a morte aguda inexplicada de um número significativo de uma espécie), mudanças climáticas, emergência de vetores. Estas informações permitem a previsão do risco de afetação dos seres humanos, a comunicação com autoridades de vigilância, testagem dos casos suspeitos e mesmo 0 estabelecimento precoce de medidas para prevenir a difusão da doença, como 0 isolamento dos casos, restrição de deslocação intra ou internacional e a promoção de campanhas de vacinação de humanos e/ou animais. Com o PREDICT, já foi contido um surto de ébola na República Democrática do Congo e prevenido um surto de febre amarela, detetada pela primeira vez numa área da Bolívia, em primatas (Kelly et al., 2020).

Modelos matemáticos têm sido desenvolvidos de modo a prever potenciais pandemias e estimar a sua mor- 


\section{PANDEMIAS, QUARENTENAS E CONTÁGIOS!}

bilidade e mortalidade. Estes podem ter em conta vários fatores que, antes ou durante a pandemia, afetam os sparke spread risk da doença, como o grau de avanço da medicina, padrões de mobilização humana, demografia, medidas de contenção, altura do ano, entre outros (Madhav et al., 2017). Além destes modelos, têm havido avanços no diagnóstico, comunicação e informação que auxiliam a prevenção pandémica, sendo que o ideal seria poder diferenciar microrganismos potencialmente patogénicos através da sequenciação molecular.

\section{QUARENTENAS}

Lisboa terá passado por duas dezenas de pestes, com uma média de mortes de seis centenas diárias, cerca de 60000 pessoas pereçeram naquela que foi a maior epidemia em toda a história de portugal até ao séc. XX, entre 1569-1570, levando D. Sebastião a convidar dois médicos espanhóis para ensinar medidas de controle apreendidas e implementadas em Sevilha como, cuidar do abastecimento alimentar, fazer fogueiras, limpar as ruas, encerrar banhos públicos, pôr os navios de quarentena, enterrar os mortos regados com cal viva, mobilizar os médicos tudo acontecia num mundo de muita terra e pouca gente !

No rescaldo da peste negra, muitos dos valores pessoais e sociais sofreram profundas alterações, pois como podia Deus bom Pai mandar semelhantes sofrimentos aos seus amados filhos? E de que valiam as reliquias, procissões e peregrinações se mesmo as crianças apodreciam numa semana?

Muitos padres faleceram no contacto com doentes e moribundos, destacando-se Roque de Montpellier (São Roque) nascido no séc XIV e canonizado no sec.XV como padroeiro dos cuidados e advogado contra o mal da peste e doenças contagiosas.

Luchino Visconti em Milão fechou a cidade, estabeleceu a quarentena, selou as casas de todos os empestados mantendo lá dentro contaminados e saudáveis, homónimo do realizador de cinema morre em 1349 envenenado pela mulher Isabella Fieschi, em Itália.Cuidadosamente o Papa Clemente VI rodeava-se de tocheiros executantes da fumigação que protegia dos ares venenosos da peste. Em Veneza foi criado o primeiro Lazaretto em 1403, um novo espaço de quarentena onde eram isolados os navios suspeitos durante seis semanas.

A Morte com a sua foice, dizimava indiscriminadamente o rei, o pobre, o justo, o pecador, conduzindo-os ás respectivas sepulturas soberbamente retratada por inúmeros artistas como Bruegel que pintou o Triunfo da Morte, num fundo de barcos naufragados, um exército de esqueletos fantasmagóricos entre árvores de folhas despidas.

\section{CONTÁGIOS}

0 ano da queda de Constantinopla, 1453, é o fim oficial da Idade Média, e o inicío dos Estados soberanos e desde então e até hoje aqui e ali sempre observamos epidemias e pandemias, cada uma deixando a sua problemática no presente e no futuro.

Thomas Moore em Utopia, Bem Johnson em The Alchimist, Francis Bacon em The New Atlantis, John Milton em Paradise Lost, referem-se á peste e aos seus efeitos devastadores : a falta de memória, o delírio e a loucura acompanhavam os homens deambulando como que ébrios passageiros de um um combóio louco sem condutor sem paragens e sem destino, quais atores de uma cena apocaliptica inimaginável.

Galeno e Hipocrates deram um sábio conselho : abandonar as cidades e quem podia assim procedia para evitar o contágio das maleitas assassinas, pois que sem remédios de confiança o risco era muito elevado, restava 0 isolamento e a quarentena (Pinto, 2021)

\section{CONCLUSÕES}

Com a evolução da medicina, têm sido criadas medidas preventivas cada vez mais eficazes, sofisticadas e mais específicas para cada doença porém algumas medidas tradicionais permanecem universalmente aplicáveis, como 0 isolamento dos infetados, a quarentena, o rastreio dos contatos próximos e a utilização de equipamento de proteção individual, tanto pelos profissionais, como pelos indivíduos infetados. Mais recentemente, 0 desenvolvimento de vacinas contribuiu para a desaceleração significativa de surtos, especialmente epidémicos e pandémicos, aliviando as infraestruturas de saúde, reduzindo a despesa pública e prevenindo a mortalidade e qua- 
dros graves das doenças em causa. Por outro lado, a criação dos testes rápidos permitiu uma maior taxa de deteção dessas doenças, não só pela rapidez dos seus resultados, mas também pela ausência de necessidade de um treino especializado, tanto para a sua execução, como a sua interpretação, podendo mesmo ser realizados pelo próprio paciente.

A história das pandemias é longa, tortuosa e cheia de segredos ainda não decifrados, a prevenção quaternária poderá ser um enorme contributo ao assegurar cuidados Iongitudinais a individuos e familias evitando 0 excessivo e premiando o necessário

Sublinhando e meditando na frase de Winston Churchill, " os que não apreendem com a História estão condenados a repeti-la".

\section{REFERÊNCIAS BIBLIOGRÁFICAS}

Antunes, J.M.G.R. (2021). A prevenção quaternária ea medicação off label na pandemia covid. Revista INFAD de Psicología. International Journal of Developmental and Educational Psychology., 1(1), 357-362.

Bellin, J (2016). L épidémie de peste noire de 1348 vue par ses contemporains. Cliotext, avri 12.

Boccaccio, G. (2019). The Decameron of Giovanni Boccaccio. Good Press.

Fong, I. W. (2017). Emerging zoonoses: A worldwide perspective. Springer. https://link.springer.com/content/pdf/10.1007/978-3-319-50890-0.pdf

Karesh, W. B., Dobson, A., Lloyd-Smith, J. O., Lubroth, J., Dixon, M. A., Bennett, M., Aldrich, S., Harrington, T., Formenty, P., Loh, E. H., Machalaba, C. C., Thomas, M. J., \& Heymann, D. L. (2012). Ecology of zoonoses: Natural and unnatural histories. The Lancet, 380(9857), 1936-1945. https://doi.org/10.1016/S01406736(12)61678-X

Kelly, T. R., Machalaba, C., Karesh, W. B., Crook, P. Z., Gilardi, K., Nziza, J., Uhart, M. M., Robles, E. A., Saylors, K., Joly, D. O., Monagin, C., Mangombo, P. M., Kingebeni, P. M., Kazwala, R., Wolking, D., Smith, W., PREDICT Consortium, \& Mazet, J. (2020). Implementing One Health approaches to confront emerging and reemerging zoonotic disease threats: Lessons from PREDICT. One Health Outlook, 2, 1. https://doi.org/10.1186/s42522-019-0007-9

Madhav, N., Oppenheim, B., Gallivan, M., Mulembakani, P., Rubin, E. \& Wolfe, N. (2017). Pandemics: risks, impacts, and mitigation. In D. T. Jamison (Eds.) et. al., Disease Control Priorities: Improving Health and Reducing Poverty. (3rd ed., pp. 315-345). The International Bank for Reconstruction and Development / The World Bank. https://www.ncbi.nlm.nih.gov/books/NBK525302/

Marien, G. The black death in the OttomanTerritories 1347-1350. Departamento de História, Universidade Bilkent, Ancara, 2009, p.19

Morse, S. S., Mazet, J. A., Woolhouse, M., Parrish, C. R., Carroll, D., Karesh, W. B., Zambrana-Torrelio, C., Lipkin, W. I., \& Daszak, P. (2012). Prediction and prevention of the next pandemic zoonosis. Lancet, 380(9857), 1956-1965. https://doi.org/10.1016/S0140-6736(12)61684-5

Porta, M. (2014). A Dictionary of epidemiology. New York, United States of America: Oxford University Press. https://doi.org/10.1093/acref/9780199976720.001.0001

Pinto, J. N. (2021). Contágios. Cadernos Ibero-Americanos de Direito Sanitário, 10(2), 253-257.

Wheelis, M (2002). Biological Warfare at the 1346 Siége of Caffa. Emerg Infect Dis 8(9):971-975 
